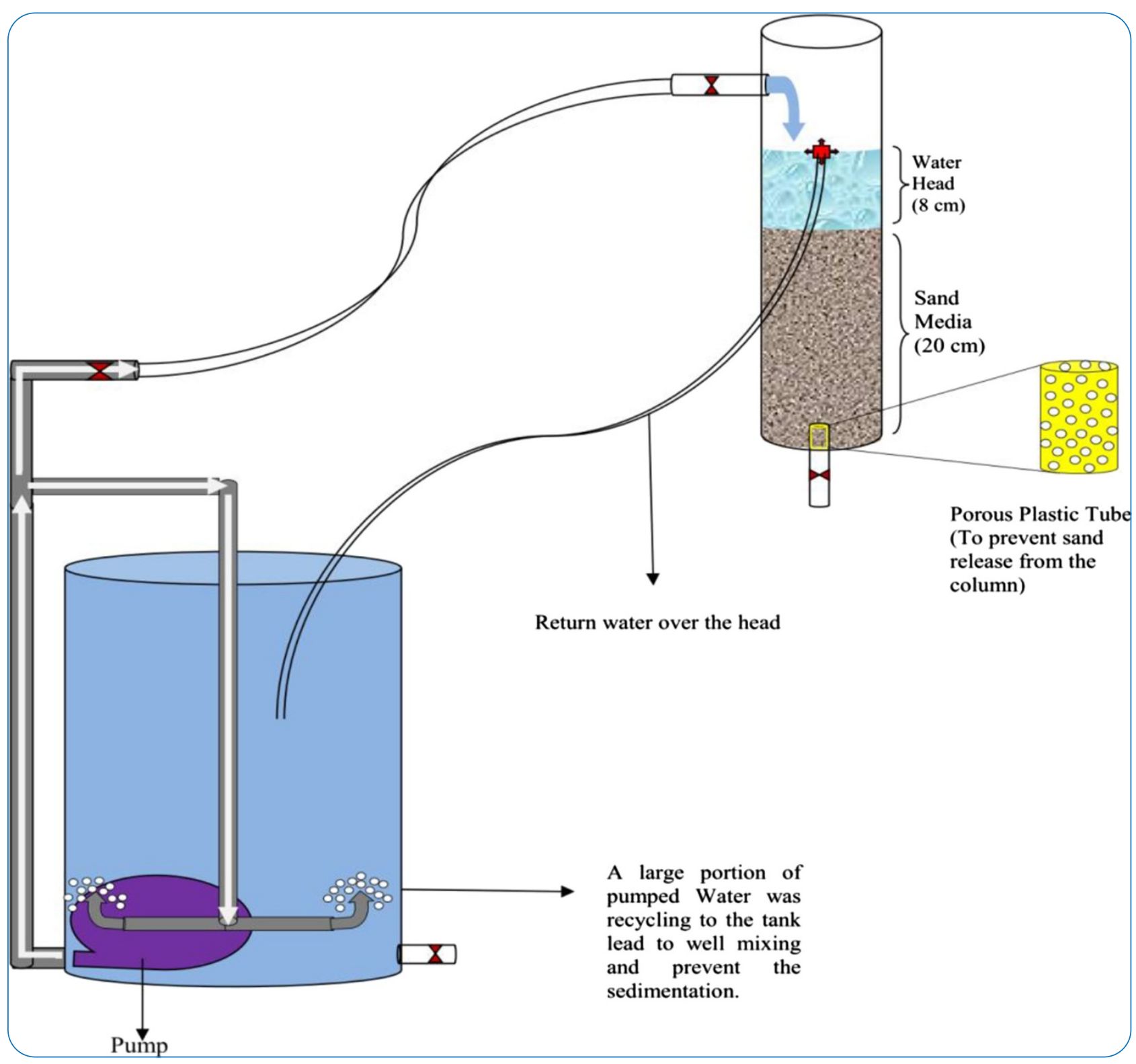

\title{
Urban runoff treatment using nano-sized iron oxide coated sand with and without magnetic field applying
}

Khiadani (Hajian) et al. 


\title{
Urban runoff treatment using nano-sized iron oxide coated sand with and without magnetic field applying
}

\author{
Mehdi Khiadani (Hajian) ${ }^{1,2}$, Mansur Zarrabi ${ }^{3}$ and Maryam Foroughi ${ }^{4^{*}}$
}

\begin{abstract}
Increase of impervious surfaces in urban area followed with increases in runoff volume and peak flow, leads to increase in urban storm water pollution. The polluted runoff has many adverse impacts on human life and environment. For that reason, the aim of this study was to investigate the efficiency of nano iron oxide coated sand with and without magnetic field in treatment of urban runoff. In present work, synthetic urban runoff was treated in continuous separate columns system which was filled with nano iron oxide coated sand with and without magnetic field. Several experimental parameters such as heavy metals, turbidity, pH, nitrate and phosphate were controlled for investigate of system efficiency. The prepared column materials were characterized with Scanning Electron Microscopy (SEM) and Energy Dispersive X-ray analysis (EDXA) instruments. SEM and EDXA analyses proved that the sand has been coated with nano iron oxide $\left(\mathrm{Fe}_{3} \mathrm{O}_{4}\right)$ successfully. The results of SEM and EDXA instruments well demonstrate the formation of nano iron oxide $\left(\mathrm{Fe}_{3} \mathrm{O}_{4}\right)$ on sand particle. Removal efficiency without magnetic field for turbidity; $\mathrm{Pb}, \mathrm{Zn}, \mathrm{Cd}$ and $\mathrm{PO}_{4}$ were observed to be $90.8 \%, 73.3 \%, 75.8 \%, 85.6 \%$ and $67.5 \%$, respectively. When magnetic field was applied, the removal efficiency for turbidity, $\mathrm{Pb}, \mathrm{Zn}, \mathrm{Cd}$ and $\mathrm{PO}_{4}$ was increased to $95.7 \%$, $89.5 \%, 79.9 \%, 91.5 \%$ and $75.6 \%$ respectively. In addition, it was observed that coated sand and magnetic field was not able to remove $\mathrm{NO}_{3}$ ions. Statistical analyses of data indicated that there was a significant difference between removals of pollutants in two tested columns. Results of this study well demonstrate the efficiency of nanosized iron oxide-coated sand in treatment of urban runoff quality; upon $75 \%$ of pollutants could be removed. In addition, in the case of magnetic field system efficiency can be improved significantly.
\end{abstract}

Keywords: Urban runoff, Iron oxide nano particles, Sand filter, Magnetic field

\section{Introduction}

Storm water runoff from paved surfaces can carry large loads of various pollutants including heavy metals, hydrocarbons, nutrients and pathogens [1-3]. These pollutants may originate from motorized vehicle emissions, automobile tires, brake pads, corrosion of pavement, chemical deposition on or near the pavement surface and anthropogenic activities [1,4]. On the other hand, since impervious surfaces such as roofs and roads dominate the land cover of urbanized areas, cities suffer from increased and more intense runoff, reduced groundwater recharge and runoff water quality [5], increased peak

\footnotetext{
* Correspondence: Maryam_foroghi88@yahoo.com

${ }^{4}$ Department of Environmental Health Engineering, School of Health,

Hamedan University of Medical Sciences, Hamedan, Iran

Full list of author information is available at the end of the article
}

flows [6] and hydrological, physico-chemical and consequent biological disturbance of the receiving waters $[7,8]$. Special attention should be paid to heavy metals in storm water runoff due to their toxicity [9]. Some of the most frequently reported metals in storm water are cadmium $(\mathrm{Cd})$, lead $(\mathrm{Pb})$ and zinc $(\mathrm{Zn})$ that are considered to be of the great concern. Concentrations of these ions in storm water commonly exceed surface water quality guidelines by 10 times or more [10]. Release of heavy metals into natural receiving waters can cause accumulation of non-biodegradable metals in the environment, causing both short-term and long-term adverse effects on human life [11]. Phosphorus (P) is the most commonly present substance in freshwater bodies subject to eutrophication [10]. Excess Nitration $(\mathrm{N})$ in storm water

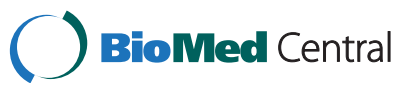


leads to saturation of nitrogen, water bloom and associated water-quality problems [12].

Several methods have been developed and used for treatment of storm water runoff from urban area. Natural and constructed wetlands, for example, have been investigated as practical alternatives for treating runoffs in several studies. These systems allow reducing primarily particulate pollutants. The constructed wetlands and retention ponds require large area and these systems were mostly applied for pollution source areas at catchment scale. Filtration of storm water through a filter system filled with adsorbents (e.g. zeolite, peat, granular activated carbon or sand) is another possible treatment method that is relatively recent innovation for treatment of runoff [13].

Iron (hydr) oxide-coated sand (IOCS) has shown to have high efficiency in removing microorganisms, turbidity and heavy metals [14]. Many studies have used IOCS to remove lead [15], arsenic [16], nickel and copper [17], organic matter [18], humic [19,20], and phosphate [21] from aqueous solution and/or wastewater. On the other hand, magnetic treatment of wastewater can be applied to eliminate heavy metals, color, phosphates and oil at low concentration. Some studies have reported that magnetic field affects properties of water such as light absorbance, $\mathrm{pH}$, zeta potential and surface tension. However, these idea have not always been confirmed [22]. In recent years, attention has been paid to the possibility of enhancing treatment of wastewater by static magnetic field. However information is not available about the effect of magnetic field on the biological degradation of wastewater organic matter [23]. Magnetic field was used to improve anaerobic ammonium oxidation in which nitrogen removal increased by $30 \%$ with $25 \%$ less time [24]. In addition, magnetic field has been used for formaldehyde biological degradation with $30 \%$ increases in removal efficiency if compared with other technologies [25].

For that reason, the aim of this study was to investigate the efficiency of sand filter coated with nano iron oxide for treatment of urban runoff. In addition to this, magnetic field was applied to the coated sand filter to find out if the magnetic field can further improve the treatment of urban runoff.

\section{Materials and methods Chemicals and reagents}

All chemical materials used in this study were provided from Merck Company. Synthesized urban runoff containing lead, zinc, cadmium, nitrate and phosphate, were prepared using stock solution of $\mathrm{PbCl}_{2}, \mathrm{ZnSO}_{4} .7 \mathrm{H}_{2} \mathrm{O}$, $\left(\mathrm{CH}_{3} \mathrm{COO}\right) 2 \mathrm{Cd} .2 \mathrm{H}_{2} \mathrm{O}, \mathrm{KNO}_{3}$ and $\mathrm{K}_{2} \mathrm{HPO}_{4}$, respectively. Turbidity and $\mathrm{pH}$ of synthesized runoff were adjusted using Kaolin and, $1 \mathrm{~N} \mathrm{HNO}_{3}$ and $\mathrm{NaOH}$ solutions, respectively. Samples were collected in $100 \mathrm{~mL}$ bottles.
The characteristics of the synthesized runoff are presented in Table 1.

\section{Sand filter media}

Filter media was packed with local quarry sands ranging between 0.85 and $2.36 \mathrm{~mm}$. Before used in column and coating, The sand was soaked in $8 \%$ nitric acid solution overnight, rinsed with deionised water to $\mathrm{pH}=7.0$ and dried at $105^{\circ} \mathrm{C}$. The sands were coated with iron oxide according the method suggested by Mostafa et al. [27]. The solution of $\mathrm{Fe}(\mathrm{III})$ was prepared by dissolving reagent grade $\mathrm{FeCl}_{3} \cdot 6 \mathrm{H}_{2} \mathrm{O}$ in deionized water. The solution was stirred with a magnetic stirrer at $200 \mathrm{rpm}$ and $0.5 \mathrm{M} \mathrm{NaOH}$ solution was added for adjusting $\mathrm{pH}$ at 9.5 \pm 0.1 and mixed for $5 \mathrm{~min}$. The mixed solution was introduced to $100 \mathrm{~g}$ sand in a conical flask and was placed in a temperature-controlled shaker at $60 \pm 1^{\circ} \mathrm{C}$, then stirred at $200 \mathrm{rpm}$ for $24 \mathrm{~h}$. After that, the coated sand was dried in an oven at $105 \pm 1^{\circ} \mathrm{C}$ for $24 \mathrm{~h}$. Finally, the prepared sands particle was washed 5-7 times with deionized water for remove uncoated iron particle, dried at $60 \pm 1^{\circ} \mathrm{C}$ for $24 \mathrm{~h}$ and used for future experiment.

\section{Column tests}

Columns used in this study were made of Plexi Glass with $5 \mathrm{~cm}$ internal diameters, $35 \mathrm{~cm}$ height, and $20 \mathrm{~cm}$ medium bed depth. Since the columns were operated in down flow mode, to avoid flow channelization, an additional $8 \mathrm{~cm}$ water head was provided on the columns surface. Two magnets of $20 \mathrm{~cm}$ high with $0.7 \mathrm{~T}$ (Tesla) magnetic charge density was mounted around one of the columns to investigated the effects of magnetic field on the removal efficiency of the pollutants from the synthesized runoff. The flow rate of runoff from both columns was adjusted at $20 \mathrm{~mL} / \mathrm{min}$ leading to $20 \mathrm{~min}$ retention time [14] of runoff in the column. Schematic of the present pilot is shown in Figure 1 (Magnets are not shown). The samples were obtained from the bottom of columns and then were analyzed for investigated parameters. Each column was operated for 60 hours, during which 10 samples were collected. The experimental data were conducted in triplicate and average value was

Table 1 Characteristics of synthesized runoff [26]

\begin{tabular}{ll}
\hline Pollutant & Concentration \\
\hline Turbidity(NTU) & 60 \\
Lead(mg/l) & 2.37 \\
Zinc(mg/l) & 2.54 \\
Cadmium(mg/l) & 0.52 \\
Nitrate(mg/l) & $4-5$ \\
Phosphate(mg/l) & $9-10$ \\
pH & $6.5-7.5$ \\
\hline
\end{tabular}




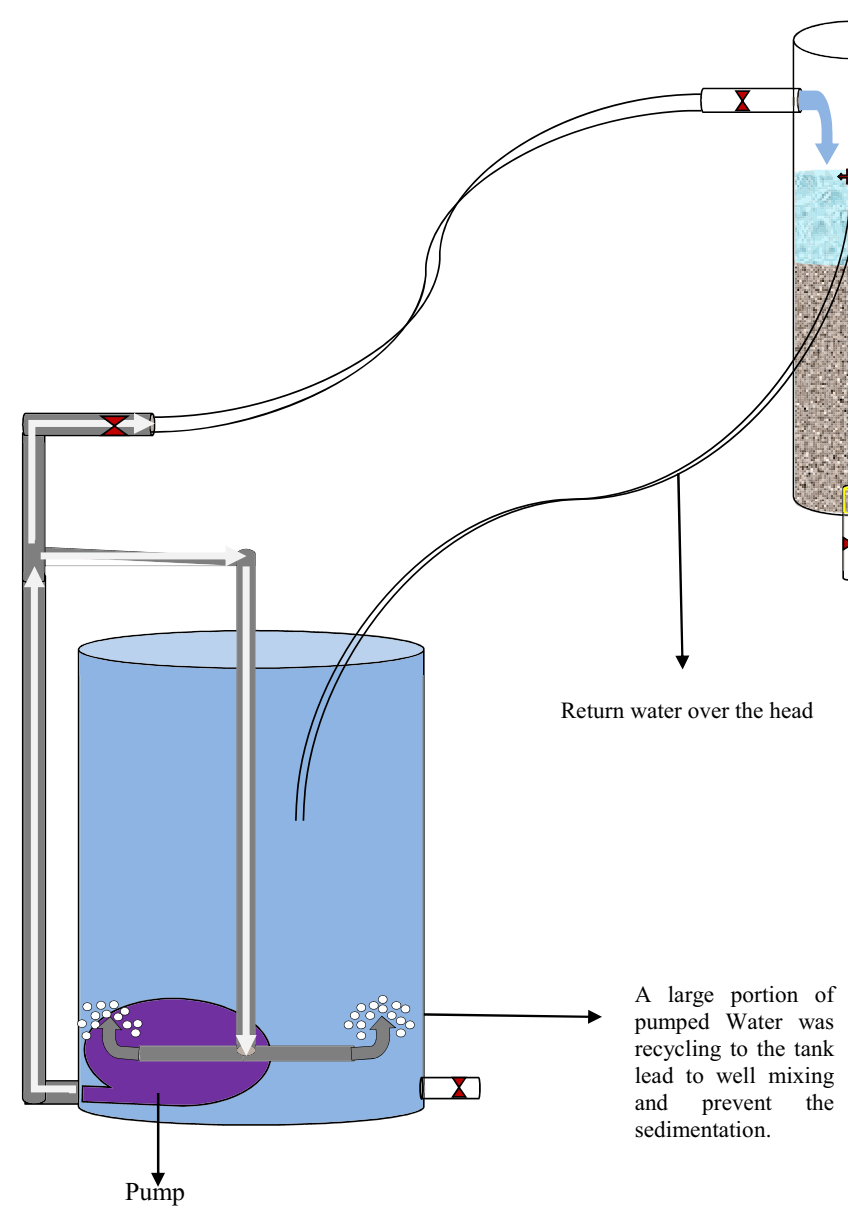

Figure 1 Schematic of the pilot-scale system used in this study.

considered. Before analysis of nitrate and heavy metals, $\mathrm{pH}$ of the samples was reduced to 2 by adding sulfuric and nitric acids, respectively [28].

\section{Instruments}

Concentration of lead $(\mathrm{Pb})$, zinc $(\mathrm{Zn})$ and cadmium $(\mathrm{Cd})$ in effluent were determined using a Perkin Elmer 2380 atomic absorption spectrometer. Nitrate and phosphate was determined using UV-vis spectrophotometer (HACH DR5000). Turbidimeter (Euteoh Instruments TN 100) was used to measure turbidity. Schott pH meter model CG-824 was used for $\mathrm{pH}$ analysis. Size and characteristics of nano particles was determined using Scanning Electron Microscope (SEM) and Energy Dispersive X-ray Analysis (EDXA).

\section{Results and discussion}

\section{Adsorbent characterization}

Figure 2a shows that the surface of uncoated sand is relatively smooth; however, the surface of coated sand with iron oxide nano particles shown in Figure $2 \mathrm{~b}$ is rough. Due to deposition of iron oxide particles on the sand surface, the coated sand has more microspores and its specific surface area may be high as in comparison with uncoated sand. This is in agreement with the results of Lai et al. who reported $0.85 \mathrm{~m}^{2} / \mathrm{g}$ and $2.76 \mathrm{~m}^{2} / \mathrm{g}$ for natural and coated sand, respectively [29].

Elemental composition of the sand was determined using EDXA spectra analysis. EDXA analysis of the unmodified sand showed the main components of the sand were Si (62.1\%) and O (20.8\%) (Figure 3a). After coating of sand with nano iron oxide, the iron content of the sand was increased to $21 \%$ of its elemental composition (Fig 3b). This is in agreement with result of Hsu et al. [15]; showing the iron content of the sand was increased by $6 \%$ after coating with nano iron oxide. In contrast to our study, the size of coated particle in Hsu and coworker study was not in nano size. Coating with nano particles caused the iron oxide penetrate to deeper layers of the sand and provide a larger interlayer space which may lead to larger micro pore diameters and spaces [15].

\section{Removal of turbidity}

Average removal efficiency of turbidity from column without magnetic field was achieved 90.8\% (Figure 4). 

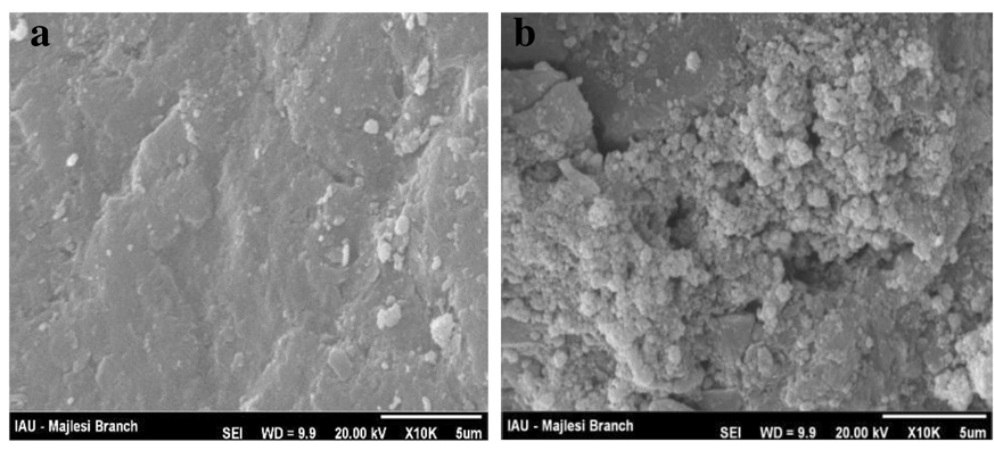

Figure 2 Scanning electron micrographs of natural sand (a), and coated sand with nano iron oxide (b).
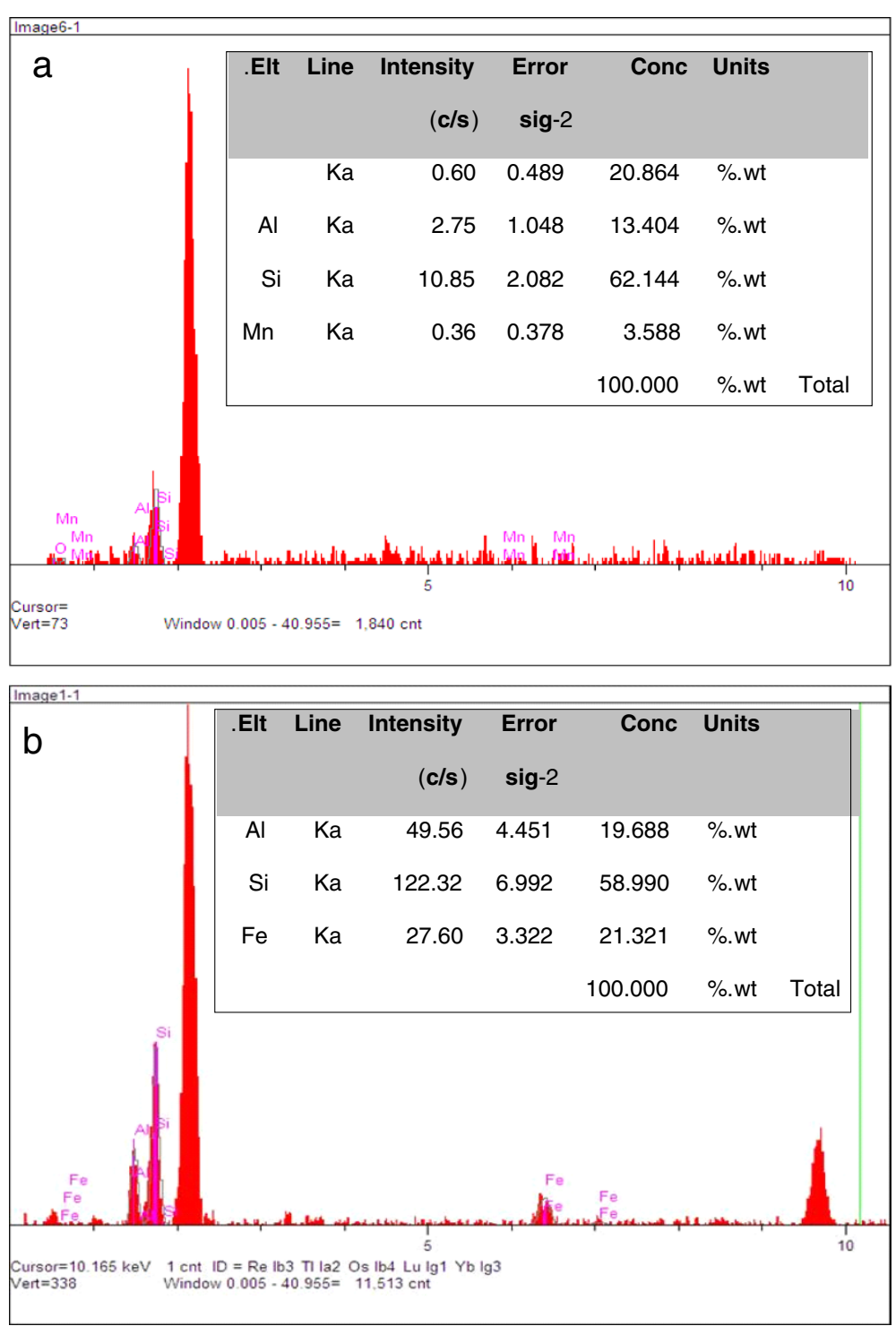

Figure 3 Energy dispersive X-ray analysis spectra of natural sand (a), and coated sand with nano iron oxide (b). 


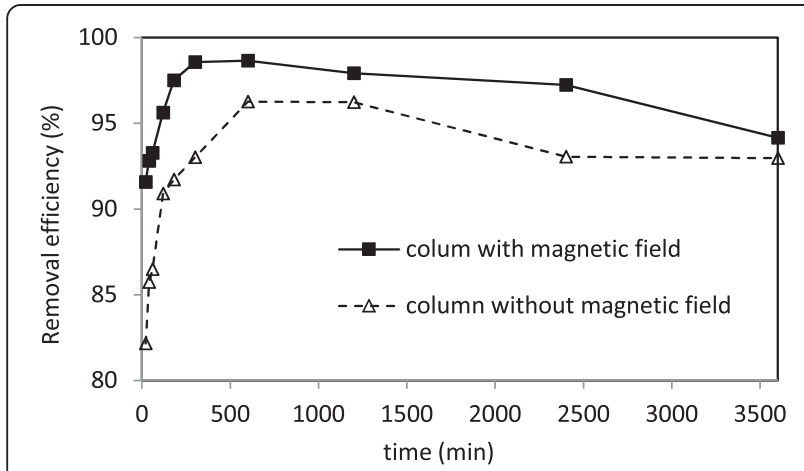

Figure $\mathbf{4}$ The removal efficiency of turbidity in columns with and without magnetic field.

The removal mechanisms in this column were filtration, settling and adsorption [30]. Once the magnetic field was applied to the column, the removal efficiency increased to $95.7 \%$. In fact, colloidal stability is influenced by the application of magnetic field, possibly indicating a reduction in charge density within the stern layer. Also it has been proposed that magnetic field reduces zeta potential of colloidal particles causing particle instability, aggregation and a more rapid sedimentation [22].

\section{Removal of lead, zinc and cadmium}

Coating sand with nano iron oxide without magnetic field improved the removal efficiency of lead, zinc and cadmium to $73.3 \%, 75.8 \%$ and $86.1 \%$, respectively (Figures 5, 6 and 7). The 54\% removal efficiency of lead from the sand filter without coating has been reported [31]. X-ray photoelectron spectroscopy (XPS) surface analysis of $\mathrm{Pb}(\mathrm{II})$-adsorbed on $\mathrm{Mg} / \mathrm{Al}$ layered double hydroxide (LDH) surfaces revealed that the preferred reaction between $\mathrm{LDH}$ and $\mathrm{Pb}(\mathrm{II})$ are surface adsorption and precipitation [15]. Thus treatment with metal oxides increases the number of adsorption sites significantly. In case of zinc and cadmium, it seems that due to the

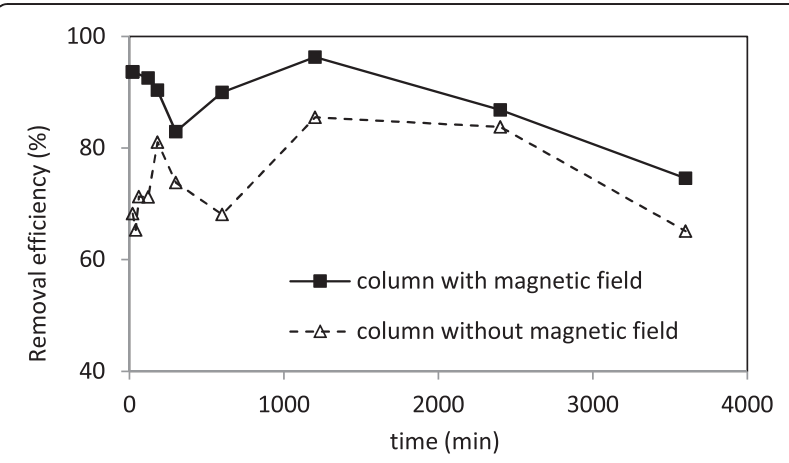

Figure $\mathbf{5}$ The removal efficiency of lead in columns with and without magnetic field.

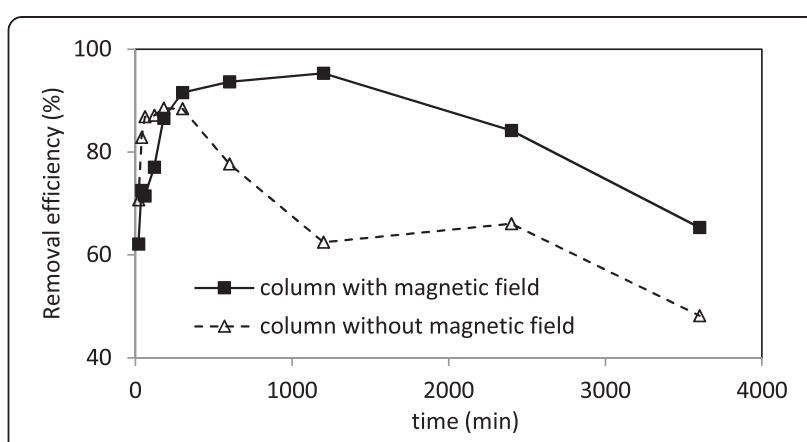

Figure 6 The removal efficiency of zinc in columns with and without magnetic field.

existence of agent groups at the surface, they lead to adsorption of the cations [32].

With applying the magnetic field to the coated sand, the removal efficiency of lead, zinc and cadmium was increased to $89.6 \%, 80 \%$, and $91.5 \%$, respectively; which are in agreement with previously published work [22]. There are not much information about the mechanism of magnetic field on soluble ions, however, magnetic force leads to increase in electrostatic interaction between positively charged ions such as lead, zinc and cadmium with adsorbent surface; followed with increase in metals adsorption capacity. It may be due to releases of free electron from adsorbent surface to bounding with metals ions. Another reason may be due to decreases in zeta potential [22] leading to increase in metal bounding with present medium.

Achak et al. reported that solution conductivity of the effluent from sand filter was reduced. They declared that this reduction is due to the adsorption of the cations on the colloids negatively charged [33]. On the other hand, it has been reported that magnetic field reduce zeta potential [22], which causes colloids instability and increases agglomeration and then speeding up settling. Moreover, adsorption to suspended solids occurs before

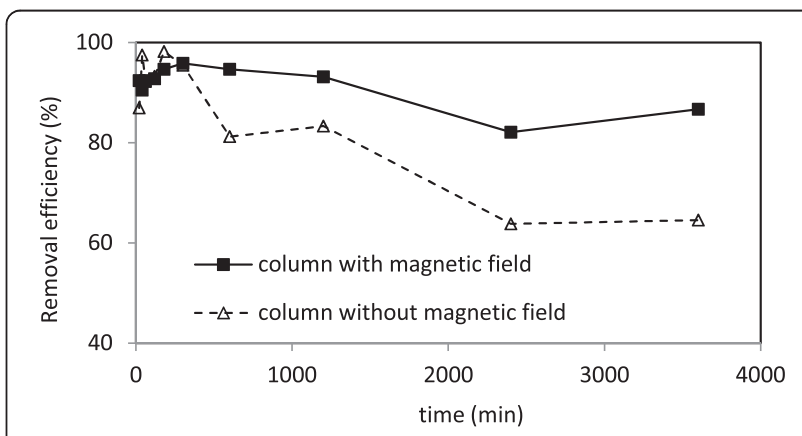

Figure 7 The removal efficiency of cadmium in columns with and without magnetic field. 


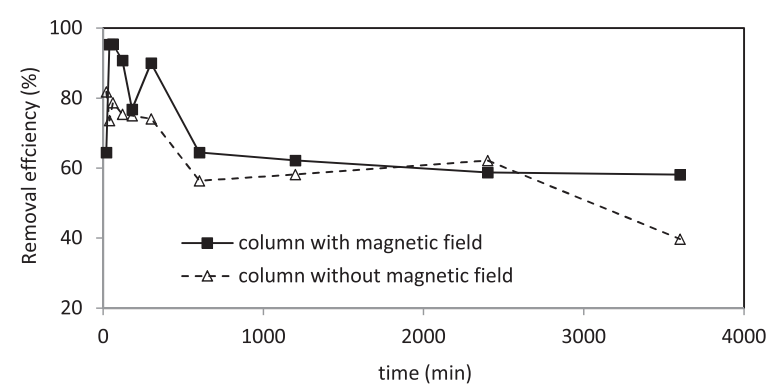

Figure 8 The removal efficiency of phosphate in columns with and without magnetic field.

settling and filtration or adsorption to substrate [30]. Therefore, an increase in removal efficiency may be is due to the occurrence of two subsequent phenomenon's: adsorption of the cations on the colloids pollutants in the first stage, and enhanced the colloids agglomeration and settling, because of zeta potential reduction, in the second stage.

\section{Removal of phosphate}

As indicated in Figure 8, 69.1\% phosphate in the column without magnetic field was removed. Our results were in agreement with previously published work for removal of phosphate with sand filter by adsorption [21,33]. In contrast, Hatt et al. reported that the sand filter is not a suitable treatment option for removal of phosphate [31].

SEM photographs in this study showed that iron oxide are well deposited on the sand, resulting in increase of the surface sites and so chance of phosphate ions adsorption. Scholes et al. reported that adsorption is physico-chemical adherence that is controlled by factors such as the particulate surface area and surface composition [30]. Moreover Achak et al. emphasized that ions are well retained by the cations of the sand such as iron and aluminum oxides [33]. Therefore, in addition to increase of surface area, the presence of iron on the surface caused to promote of adsorption, due to adsorption of the ions onto iron deposits.

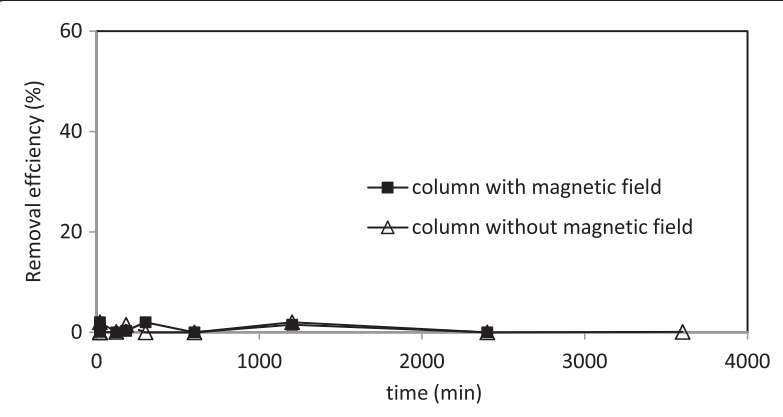

Figure 9 The removal efficiency of nitrate in columns with and without magnetic field.
Since phosphate and arsenic are in the same group in the periodic table and their ionic charge and size are very similar [27], Boujelben et al. declared phosphate ions are as models for removal of similar pollutant (i.e. arsenates and antimonies) [21]. Besides, it has been reported that one reason for higher efficiency of iron oxide coated sand for As (III) may be is due to formation of ferric hydroxide in the aqueous solution responsible for the co-precipitation of the ions on the surface of the adsorbent [34]. Therefore, it well demonstrated that only adsorption is not contributed in the phosphate removal. According this, Mostafa et al. declared that if desorption rate was slower than adsorption rate, chemical mechanism is contribute in the ion removal, and since this relationship was established in their study, they conclude that chemical bonding was formed between arsenic ions and the coated surface [27]. Therefore, in addition to adsorption, formation of chemical bonding between phosphate ions and the coated surface was contributed in the phosphate ion removal. The coated sand with nano iron oxide with magnetic field increased the removal efficiency of phosphate to $75 \%$. As it was explained previously, magnetic field could reduce zeta potential and causes insatiability which leads to adsorption and agglomeration of phosphate. Moreover, magnetic force breaks hydrogen bonds between water molecules, so the ions become separated and combine with elements (such as $\mathrm{Pb}, \mathrm{P}, \mathrm{Ni}$, etc.) and precipitate [22].

\section{Removal of nitrate}

Neither the sand filter coated with nano iron oxide nor magnetic field was able to remove nitrate form the synthesized runoff (Figure 9). It has been reported that biochemical process may help to remove nitrate [31]. This is basically due to the formation of biofilm which allows oxidation of all nitrogen forms in the filter [33].

Statistical analyses of data indicated that there was a significant difference between removals of pollutants in two columns. In case of turbidity, lead, zinc, cadmium and phosphate, prob $>|t|$ is $0.005,0.03,0.03,0.005$, and 0.007 respectively (all less than 0.05 ).

\section{Conclusions}

In present study, natural sand and nano sized iron coated sand with and without applying magnetic field was used for treatment of synthetic urban runoff. Results indicate that nano sized iron oxide-coated sand has a significant efficiency to improve urban runoff quality. Nano iron coated sand was able to remove $75 \%$ of pollutant in average. In addition, in the case of magnetic field, removal efficiency was improved significantly; showing effectives of nano iron coated sand in the presence of magnetic field. Our results well demonstrate that present system is effective methods as compared with other existing methods for treatment of 
urban runoff containing, phosphate, turbidity, cadmium, lead and zinc. Although the real urban runoff must be applied to achieve real results and further studies are needed to implement of this system on a large scale.

\section{Competing interests}

The authors declare that they have no competing interests.

\section{Authors' contributions}

MK (Hajian) was involved in experimental parts and takes the initial samples from pilot plant. MZ reviewed the final manuscript and also involved in experimental parts. MF was involved in the design of the Study, analysis and interpretation of data, drafting the initial manuscript. All authors read and approved the final manuscript.

\section{Acknowledgements}

The authors would like to thank the Esfahan University of Medical Sciences for supporting of this work. In addition, we thank Hamadan University of Medical Sciences for supporting partial laboratory analysis.

\section{Author details}

${ }^{1}$ School of Engineering, Edith Cowan University, WA, Australia. ${ }^{2}$ Department of Environmental Health Engineering, Environment Research Center, School of Health, Isfahan University of Medical Sciences, Isfahan, Iran. ${ }^{3}$ Department of Environmental Health Engineering, Faculty of Health, Alborz University of Medical Sciences, Karaj, Iran. ${ }^{4}$ Department of Environmental Health Engineering, School of Health, Hamedan University of Medical Sciences, Hamedan, Iran.

Received: 21 December 2012 Accepted: 2 November 2013 Published: 20 December 2013

\section{References}

1. Jang $Y-C$, Jain $P$, Tolaymat $T$, Dubey B, Singh $S$, Townsend $T$ : Characterization of roadway stormwater system residuals for reuse and disposal options. Sci Total Environ 2010, 408(4):1878-1887.

2. Karlsson K, Viklander M, Scholes L, Revitt M: Heavy metal concentrations and toxicity in water and sediment from stormwater ponds and sedimentation tanks. J hazard mater 2010, 178(11):612-618.

3. Parker J, Mclntyre D, Noble R: Characterizing fecal contamination in stormwater runoff in coastal North Carolina, USA. Water Res 2010, 44:4186-4194

4. Camponelli KM, Lev SM, Snodgrass JW, Landa ER, Casey RE: Chemical fractionation of $\mathrm{Cu}$ and $\mathrm{Zn}$ in stormwater, roadway dust and stormwater pond sediments. Environ Pollut 2010, 158(4):2143-2149.

5. Schroll E, Lambrinos J, Righetti T, Sandrock D: The role of vegetation in regulating stormwater runoff from green roofs in a winter rainfall climate. Ecol Eng 2011, 37(3):595-600.

6. Blecken G-T, Zinger Y, Deletić A, Fletcher TD, Hedström A, Viklander M: Laboratory study on stormwaterbiofiltration: nutrient and sediment removal in cold temperatures. J Hydrol 2010, 394(14):507-514.

7. Hurley SE, Forman RT: Stormwater ponds and biofilters for large urban sites: modeled arrangements that achieve the phosphorus reduction target for Boston's Charles River. USA Ecol Eng 2011, 37(13):850-863.

8. Tixier G, Lafont M, Grapentine L, Rochfort Q, Marsalek J: Ecological risk assessment of urban stormwater ponds: literature review and proposal of a new conceptual approach providing ecological quality goals and the associated bioassessment tools. Ecol Indic 2011, 11(7):1497-1506.

9. Lindblom E, AhIman S, Mikkelsen PS: Uncertainty-based calibration and prediction with a stormwater surface accumulation-washoff model based on coverage of sampled $\mathrm{Zn}, \mathrm{Cu}, \mathrm{Pb}$ and $\mathrm{Cd}$ field data. Water Res 2011, 45(9):3823-3835.

10. Okochi NC, McMartin DW: Laboratory investigations of stormwater remediation via slag: effects of metals on phosphorus removal. J hazard mater 2011, 187(16):250-257.

11. Wu P, Zhou Y-S: Simultaneous removal of coexistent heavy metals from simulated urban stormwater using four sorbents: a porous iron sorbent and its mixtures with zeolite and crystal gravel. J hazard mater 2009, 168(6):674-680.
12. Collins KA, Lawrence TJ, Stander EK, Jontos RJ, Kaushal SS, Newcomer TA, Grimm NB, Cole Ekberg ML: Opportunities and challenges for managing nitrogen in urban stormwater: a review and synthesis. Ecol Eng 2010, 36(13):1507-1519.

13. Fuerhacker M, Haile TM, Monai B, Mentler A: Performance of a filtration system equipped with filter media for parking lot runoff treatment. Desalination 2011, 275(3):118-125.

14. Ahammed MM, Meera V: Metal oxide/hydroxide-coated dual-media filter for simultaneous removal of bacteria and heavy metals from natural waters. J hazard mater 2010, 181(9):788-793.

15. Eren E: Removal of lead ions by Unye (Turkey) bentonite in iron and magnesium oxide-coated forms. J hazard mater 2009, 165(11):63-70.

16. Hsu J-C, Lin C-J, Liao C-H, Chen S-T: Removal of As (V) and As (III) by reclaimed iron-oxide coated sands. J hazard mater 2009, 153(6):817-826.

17. Boujelben N, Bouzid J, Elouear Z: Adsorption of nickel and copper onto natural iron oxide-coated sand from aqueous solutions: study in single and binary systems. J hazard mater 2009, 163(9):376-382.

18. Ding C, Yang X, Liu W, Chang Y, Shang C: Removal of natural organic matter using surfactant-modified iron oxide-coated sand. J hazard mater 2010, 174(13):567-572.

19. Yang X, Flynn R, von der Kammer F, Hofmann T: Quantifying the influence of humic acid adsorption on colloidal microsphere deposition onto iron-oxide-coated sand. Environ Pollut 2010, 158(8):3498-3506.

20. Yang X, Flynn R, von der Kammer F, Hofmann T: Influence of ionic strength and $\mathrm{pH}$ on the limitation of latex microsphere deposition sites on iron-oxide coated sand by humic acid. Environ Pollut 2011, 159(9):1896-1904.

21. Boujelben N, Bouzid J, Elouear Z, Feki M, Jamoussi F, Montiel A: Phosphorus removal from aqueous solution using iron coated natural and engineered sorbents. J hazard mater 2008, 151(13):103-110.

22. Alkhazan MMK, Saddiq AAN: The effect of magnetic field on the physical, chemical and microbiological properties of the lake water in Saudi Arabia. J EvolBiol Res 2010, 2(3):7-14.

23. Tomska A, Wolny L: Enhancement of biological wastewater treatment by magnetic field exposure. Desalination 2008, 222(21):368-373.

24. Liu S, Yang F, Meng F, Chen H, Gong Z: Enhanced anammox consortium activity for nitrogen removal: Impacts of static magnetic field. J biotechnol 2008, 138(1):96-102.

25. Lebkowska M, Rutkowska-Narożniak A, Pajor E, Pochanke Z: Effect of a static magnetic field on formaldehyde biodegradation in wastewater by activated sludge. Biogeosciences 2011, 102(14):8777-8782.

26. Khiadani M, Foroughi M, Amin MM: Improving urban run-off quality using iron oxide nanoparticles with magnetic field. Desalin Water Treat 2013, 58(3):1-5.

27. Mostafa M, Chen Y-H, Jean J-S, Liu C-C, Lee Y-C: Kinetics and mechanism of arsenate removal by nanosized iron oxide-coated perlite. J hazard mater 2011, 187(15):89-95.

28. AWWA (American Water Work Accocation): Standard methods for the examination of water and wastewater. 21st edition. Washington DC: AWWA; 2005.

29. Lai C, Lo S, Chiang H: Adsorption/desorption properties of copper ions on the surface of iron-coated sand using BET and EDAX analyses. Chemosphere 2000, 41(14):1249-1255.

30. Scholes L, Revitt DM, Ellis JB: A systematic approach for the comparative assessment of stormwater pollutant removal potentials. $J$ environ manage 2008, 88(3):467-478.

31. Hatt BE, Fletcher TD, Deletic A: Treatment performance of gravel filter media: implications for design and application of stormwater infiltration systems. Water Res 2007, 41(12):2513-2524.

32. Waseem M, Mustafa S, Naeem A, Koper G, Shah $\mathrm{K}: \mathrm{Cd}<\sup >2+</$ sup $>$ sorption characteristics of iron coated silica. Desalination 2011, 277(7):221-226.

33. Achak M, Mandi L, Ouazzani N: Removal of organic pollutants and nutrients from olive mill wastewater by a sand filter. J environ manage 2009, 90(3):2771-2779.

34. Gupta V, Saini V, Jain N: Adsorption of As (III) from aqueous solutions by iron oxide-coated sand. J Colloid Interface Sci 2005, 288(4):55-60.

doi:10.1186/2052-336X-11-43

Cite this article as: Khiadani (Hajian) et al:: Urban runoff treatment using nano-sized iron oxide coated sand with and without magnetic field applying. Journal of Environmental Health Sciences \& Engineering 2013 11:43. 